\title{
Outcome of Gastroesophageal Reflux Therapy in Children with Persistent Otitis Media with Effusion
}

\author{
Reem Elbeltagy ${ }^{10}$ Marwa Abdelhafeez ${ }^{2(1)}$ \\ ${ }^{1}$ Department of Otorhinolaryngology, Audio-Vestibular Medicine, \\ Faculty of Medicine, Zagazig University, El Sharkia, Egypt \\ 2 Department of Otorhinolaryngology, Faculty of Medicine, Minia \\ University, Minia, Egypt \\ Int Arch Otorhinolaryngol 2022;26(1):e58-e62.
}

Address for correspondence Reem Elbeltagy, Zagazig University Faculty of Human Medicine, Minia University, Minia, Egypt (e-mail: reem.elbeltagy@yahoo.com).

\begin{abstract}
Keywords

- otitis media with effusion

- gastroesophageal reflux

- child

- prevalence
\end{abstract}

Introduction Otitis media with effusion (OME) is considered one of the most common disorders that affect children during the first years of life. There are many risk factors of persistent middle ear effusion; one of these risk factors is gastroesophageal reflux. Association between persistent OME and gastroesophageal reflux diseases (GERDs) could be explained by respiratory tract infections, insufficient ciliary clearance, and poor drainage of the Eustachian tube.

Objective To investigate whether the control of gastroesophageal reflux plays a role in the management of persistent OME and decreases tympanostomy tube insertion Method A cross-sectional study was conducted on 50 children complaining of persistent OME. Their ages ranged between 5 and 12 years old. All children were subjected to full history taking, audiological assessment and 24-hour esophageal $\mathrm{pH}$ monitoring. The study group was divided according to $\mathrm{pH}$ results into two groups: GERD positives and GERD negatives.

Result The prevalence of GERD in persistent OME was $58 \%$. There were statistically significant differences in the hearing levels and middle ear condition before and after the treatment $(p<0.05)$. The percentage of improvement of children complaining of persistent OME after antireflux treatment was $52 \%$.

Conclusion Gastroesophageal reflux disease should be considered in patients with persistent OME. The administration of proton pump inhibitor (PPI) can set aside superfluous surgical treatment (such as tympanostomy).

\section{Introduction}

Otitis media with effusion (OME) is considered one of the most common disorders that affect children during the early years of their life. ${ }^{1}$ Its true prevalence is difficult to estimate as it is a silent disorder. Moreover, according to a previous study, ${ }^{2}$ its prevalence in children is $\sim 16.5 \%$, and between 2.2 and $4.8 \%$ worldwide. ${ }^{3}$ About $90 \%$ of children have reported at least one episode of OME by the age of 4 years old. One of the most common causes of hearing loss in children is persistent middle-ear effusion, which lasts for $>3$ months, with no improvement even after treatment. ${ }^{4}$

Many risk factors exist for persistent middle ear effusion, one of them being gastroesophageal reflux (GER), ${ }^{5}$ which is the reflux of gastric content beyond the oropharynx, the larynx, and the nasopharynx. Children with GER may complain of different symptoms such as heartburn, vomiting, and regurgitation. $^{6}$ The association between persistent OME and received

April 25, 2020

accepted

August 23, 2020

published online

March 29, 2021
DOI https://doi.org/ $10.1055 / \mathrm{s}-0040-1718958$. ISSN 1809-9777.

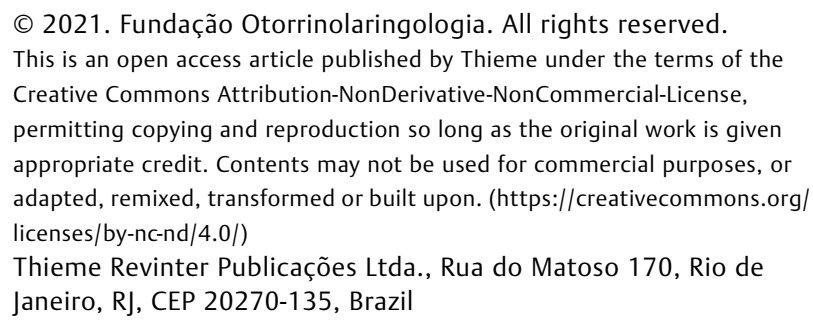

(C) 2021. Fundação Otorrinolaringologia. All rights reserved. This is an open access article published by Thieme under the terms of the Creative Commons Attribution-NonDerivative-NonCommercial-License, permitting copying and reproduction so long as the original work is given appropriate credit. Contents may not be used for commercial purposes, or adapted, remixed, transformed or built upon. (https://creativecommons.org/ licenses/by-nc-nd/4.0/) Thieme Revinter Publicações Ltda., Rua do Matoso 170, Rio de Janeiro, RJ, CEP 20270-135, Brazil 
gastroesophageal reflux diseases (GERDs) can be explained by respiratory tract infections, insufficient ciliary clearance, and poor drainage of the Eustachian tube. ${ }^{7}$

Two studies were conducted on rats, and in the first one, Heavner et al. ${ }^{8}$ concluded that the repeated exposure of the Eustachian tube to the main components of gastric juice (hydrochloric acid [HCL] and pepsin) may lead to Eustachian tube dysfunction, followed by OME. In the other study, the authors found that mucociliary clearance was affected in rats exposed to HCL. ${ }^{9}$

A previous study conducted on 54 children, aged between 2 and 8 years old, who complained of glue ear, reported an increase in the level of pepsin/pepsinogen in effusion samples compared with its level in the serum, suggesting that GER may be the cause of persistent OME. ${ }^{10}$

The presence of bothersome symptoms and complications of the reflux of gastric content can be roughly diagnosed as GERD. ${ }^{11}$ The diagnosis of GERD can be confirmed by esophageal $\mathrm{PH}$ monitoring with a double probe in which acid may pass the anatomical barrier of the upper esophageal sphincter and come into contact with the extraesophageal mucosa. ${ }^{12}$ Proton pump inhibitor (PPI) such as lansoprazole or omeprazole is considered the current treatment for GERD. ${ }^{13}$ This medication is safe for use in children as young as 2 years old. ${ }^{14}$ While the tympanostomy tube (TT) is considered the standard treatment for persistent OME, it is not completely safe. The hazards of TT insertion include otorrhea, perforation of the tympanic membrane, granulation tissue, myringosclerosis, segmental atrophy of the eardrum, and acquired cholesteatoma. ${ }^{15}$

The study of Beyea et al $^{16}$ concluded that TT patients have a higher risk of chronic ear disease surgery than patients with recurrent middle ear disease.

Therefore, the present study aims to investigate whether the control of gastroesophageal reflux plays a role in the management of persistent OME and decreases tympanostomy tube insertion.

\section{Subject and Method}

\section{Study Design \& Subjects}

A cross-sectional study was conducted in the Otorhinolaryngology department and Pediatric Gastroenterology Unit in a teaching university hospital. Concerning ethical aspects, the parents and/or those responsible for the children were given an Informed Consent Form (ICF), and so did the children themselves receive the Informed Assent Form. Both documents contained the objectives of the study, the steps in carrying it out, and its risks and benefits. Furthermore, the confidentiality of the data was guaranteed by the signing of the researchers of the Confidentiality Agreement.

The present study assessed 50 children complaining of persistent OME (OME for $>3$ months with no improvement even after obtaining medical treatment). ${ }^{4}$

The eligibility criteria established for the present research were: 1) children between the ages of 5 and 12 years old; 2) the presence of bilateral persistent OME for at least 3 months with no improvement even after obtaining medical treatment, based on: a) clinical history: the history of hearing loss, aural fullness and/or ear rubbing; b) pneumatic otoscopy: observations suggestive of OME include the presence of a dull tympanic membrane, presence of a level of effusion, decrease or nonmotility of the tympanic membrane, retraction of the tympanic membrane; c) tympanometry: type B (flat curve tympanogram with normal external ear canal volume) with absent acoustic reflex; d) pure-tone audiometry: the conductive hearing loss diagnosed by elevated pure tone threshold with air bone gap (ABG) should be at least $10 \mathrm{~dB}$ and bone conduction threshold should be better than $25 \mathrm{~dB}$. The exclusion criteria were: a) children with a medical history or concurrent conditions known to increase the incidence of OME, including cleft palate, neurologic delay, allergic rhinitis or Down syndrome, were excluded. b) patients with structural abnormalities of the tympanic membrane, including atelectasis, or deep retraction pockets, were also excluded.

All participants in the current study were subjected to the following

1. Full history taking including

- Personal history (age, name and gender)

- History of hearing loss, tinnitus, discharge, earache, headache

- History of GERD symptoms (heartburn, vomiting)

- Past history of systemic disease, physical trauma, acoustic trauma, ototoxic drug and operations

2- Otological examination: preauricular region, ear pinna, postauricular region, and tympanic membrane.

\section{3- Basic audiological evaluation}

a-Pure-tone audiometry using Orbiter 922 GM (Otomtrix, Denmark): This included

- Air conduction: (Air conduction hearing thresholds were determined by the frequency range of 0.250 and $8 \mathrm{KHz}$ )

- Bone-conduction: (bone conduction hearing thresholds were determined by the frequency range of 0.500 and $4 \mathrm{KHz}$.

- Hearing thresholds $>25 \mathrm{~dB}$ were considered as hearing loss (HL).

b- Speech audiometry Speech Reception Threshold (SRT) using Arabic spondee words and the Word discrimination scores (WDS) using Arabic phonetically balanced words

c- Immittancemetry using Amplaid 724 (Amplifon, Italy). This included tympanometry and acoustic reflex threshold measurement.

4- 24-hour esophageal $\mathrm{pH}$ monitoring.

Children were assessed for GERD symptoms (acid regurgitation and heartburn) and all those having GERD were clinically referred to the Pediatric Gastroenterology Unit and underwent a prolonged ambulatory 24-hour esophageal pH monitoring.

Diagnosis of GERD was based on the presence of GERDrelated complaints and a decrease in esophageal $\mathrm{pH}$ to $<4$ for at least 15 seconds. Thereafter, the patients were divided into two groups: GERD positive and GERD negative.

\section{Procedure}

The parents were instructed on antireflux precautions, antireflux therapy was prescribed by a pediatric Gastroenterology specialist. The antireflux precautions were avoiding 
chocolate, acidic or fruit juices, tomatoes, and fatty or greasy foods; avoiding eating before bedtime; and elevating the head of the bed. Also, the parents were instructed to avoid smoking near the child.

The GERD positive group was given the PPI lansoprazole for between 8 and 12 weeks; 2 dosages of lansoprazole were administered based on the weight of the child. Children weighing $<30 \mathrm{~kg}$ were given $15 \mathrm{mg}$ lansoprazole per day, while children weighing $>30 \mathrm{~kg}$ were given $30 \mathrm{mg}$ per day. ${ }^{4}$

Each month, the children returned to the clinic for a follow-up visit. At each follow-up visit, the physician completed a follow-up data sheet documenting, history taking, GERD symptoms and basic audiological evaluation. After 3 months; children who did not improve were referred to an ear, nose and throat (ENT) clinic for placement of a tympanostomy tube. Improvement was defined as improvement in middle ear effusion and audiometric testing.

\section{Statistical Analysis}

The data were analyzed by IBM SPSS Statistics for Windows, version 24.0 (IBM Corp, Armonk, NY, USA). Continuous variables were presented as the mean \pm standard deviation (SD) and range. Numerical variables were presented by the count and percentage. The independent-samples $t$-test was used to determine if a difference exists between the means of two independent groups on a continuous dependent variable. The chi-squared test of association was used to discover if there was a relationship between two categorical variables. The differences were considered significant at $p<.05$. All statistical comparisons were two-tailed.

\section{Results}

\section{Baseline Characteristics of the Study Groups}

Ages ranged between 5 and 12 years old with a mean age of $8.4 \pm 1.2$ years old. They were 22 females ( $44 \%$ ) and 28 males (56\%).

\section{The Distribution of Study Group According to 24-hour Esophageal pH Monitoring}

The study group was divided into two groups: GERD positives (58\%) and GERD negatives (42\%). The prevalence of GERD in persistent OME was 58\%, as shown in - Fig. 1.

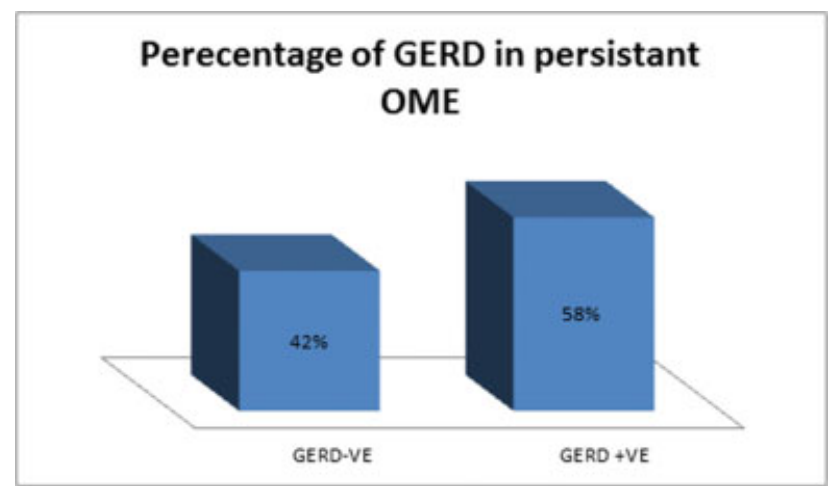

Fig. 1 Percentage of gastroesophageal reflux in persistent otitis media with effusion.

\section{Basic Audiological Assessment}

- Tables 1 and $\mathbf{2}$ show the mean of pure-tone hearing thresholds in the right and left ears of the children with positive GERD before and after treatment with antireflux therapy. There was a statistically significant difference in the hearing levels before and after the treatment $(p<0.05)$.

Table 1 Mean, Standard deviation range of pure tone thresholds in $\mathrm{dB} \mathrm{HL}$ in the right ear of 29 patients of the $(+)$ GERD before and after treatment

\begin{tabular}{|c|c|c|c|c|}
\hline \multirow[t]{2}{*}{$\begin{array}{l}\text { Frequency } \\
(\mathrm{Hz})\end{array}$} & $\begin{array}{l}\text { Before } \\
\text { treatment }\end{array}$ & $\begin{array}{l}\text { After } \\
\text { treatment }\end{array}$ & & \\
\hline & $\begin{array}{l}\text { Mean } \\
\pm \text { SD }\end{array}$ & $\begin{array}{l}\text { Mean } \\
\pm \text { SD }\end{array}$ & $\mathrm{t}$ & p-value \\
\hline 250 & $\begin{array}{l}35.5+9.5 \\
20-50\end{array}$ & $\begin{array}{l}16.3+6.8 \\
10-40\end{array}$ & 8.8501 & $0.0001^{*}$ \\
\hline 500 & $\begin{array}{l}33.6+9.4 \\
20-50\end{array}$ & $\begin{array}{l}18.2+6.1 \\
10-40\end{array}$ & 7.4008 & $0.0001^{*}$ \\
\hline 1000 & $\begin{array}{l}32.4+5.8 \\
20-40\end{array}$ & $\begin{array}{l}18.2+6.4 \\
10-35\end{array}$ & 8.8536 & $0.0001^{*}$ \\
\hline 2000 & $\begin{array}{l}31.3+4.7 \\
20-40\end{array}$ & $\begin{array}{l}21.1+5.2 \\
10-30\end{array}$ & 7.6829 & $0.0001^{*}$ \\
\hline 4000 & $\begin{array}{l}32.5+4.2 \\
20-40\end{array}$ & $\begin{array}{l}17.2+4.3 \\
10-30\end{array}$ & 13.7074 & $0.0001^{*}$ \\
\hline 8000 & $\begin{array}{l}33.2+6.8 \\
20-40\end{array}$ & $\begin{array}{l}18.9+4.7 \\
10-30\end{array}$ & 9.3160 & $0.0001^{*}$ \\
\hline
\end{tabular}

Abbreviation: SD, standard deviation.

$p \geq 0.05$ : nonsignificant.

${ }^{*} p<0.05$ : significant.

(+) GERD Presence of GERD related complaints and a decrease in esophageal $\mathrm{pH}$ to $<4$ for at least 15 seconds.

Table 2 Mean, Standard deviation, range of pure tone thresholds in $\mathrm{dB} \mathrm{HL}$ in the left ear of 29 patients of the $(+)$ GERD before and after treatment

\begin{tabular}{|l|l|l|l|l|}
\hline $\begin{array}{l}\text { Frequency } \\
(\mathrm{Hz})\end{array}$ & $\begin{array}{l}\text { Before } \\
\text { treatment }\end{array}$ & $\begin{array}{l}\text { After } \\
\text { treatment }\end{array}$ & & \\
\cline { 2 - 5 } & $\begin{array}{l}\text { Mean } \\
\pm \mathrm{SD}\end{array}$ & $\begin{array}{l}\text { Mean } \\
\pm \mathrm{SD}\end{array}$ & $\mathrm{t}$ & $p$-value \\
\hline $\mathbf{2 5 0}$ & $\begin{array}{l}35.1+8.8 \\
20-50\end{array}$ & $\begin{array}{l}17.9+7.7 \\
10-40\end{array}$ & 7.6910 & $0.0001^{*}$ \\
\hline $\mathbf{5 0 0}$ & $\begin{array}{l}32.2+8.1 \\
20-50\end{array}$ & $\begin{array}{l}18.4+6.4 \\
10-40\end{array}$ & 7.1988 & $0.0001^{*}$ \\
\hline $\mathbf{1 0 0 0}$ & $\begin{array}{l}31.5 \pm 5.8 \\
20-40\end{array}$ & $\begin{array}{l}17.9+6.2 \\
10-35\end{array}$ & 8.6264 & $0.0001^{*}$ \\
\hline $\mathbf{2 0 0 0}$ & $\begin{array}{l}30.8 \pm 3.3 \\
20-40\end{array}$ & $\begin{array}{l}20.5+5.1 \\
10-30\end{array}$ & 9.1311 & $0.0001^{*}$ \\
\hline $\mathbf{4 0 0 0}$ & $\begin{array}{l}32.7 \pm 4.2 \\
15-35\end{array}$ & $\begin{array}{l}17.5+4.4 \\
10-30\end{array}$ & 13.4568 & $0.0001^{*}$ \\
\hline $\mathbf{8 0 0 0}$ & $33.1 \pm 6.1$ & $\begin{array}{l}19.6+4.5 \\
10-30\end{array}$ & 9.5907 & $0.0001^{*}$ \\
\hline
\end{tabular}

Abbreviation: SD, standard deviation. $p \geq 0.05$ : nonsignificant.

${ }^{*} p<0.05$ : significant.

(+) GERD Presence of GERD related complaints and a decrease in esophageal $\mathrm{pH}$ to $<4$ for at least 15 seconds. 


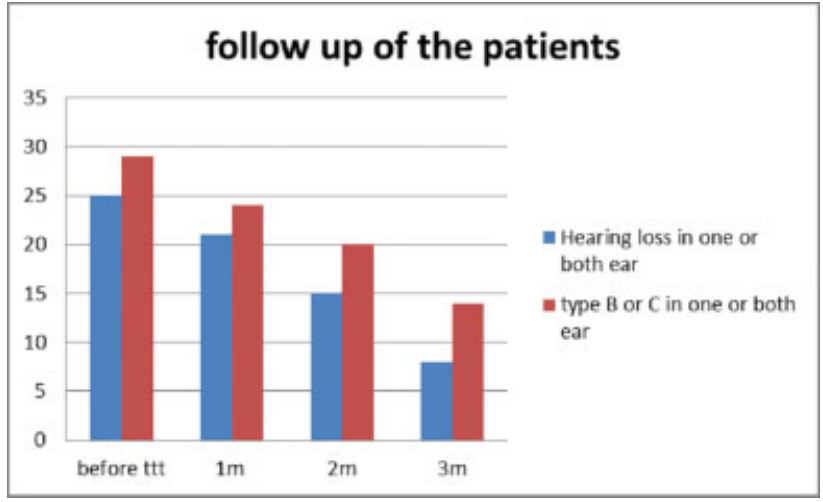

Fig. 2 Follow up of the middle ear condition and hearing loss in the patients

-Fig. 2 shows the follow up of the middle ear condition and the hearing loss in the patients before and after (1-23 Months) antireflux therapy. There was a statistically significant difference $(p<0.05)$.

As demonstrated in -Table 3 , the percentage of the improvement of persistent OME after antireflux treatment was $52 \%$, and the percentage of the improvement of the hearing thresholds was $68 \%$. There was a statistically significant difference $(p<0.05)$.

\section{Discussion}

Otitis media with effusion and GERD are considered two of the most common diseases in children, and this encouraged researchers to prove there is an association between the two diseases and to find a causative relationship between them. ${ }^{17}$ A previous study noticed the presence of pepsin in the middle ear effusion among children complaining of OME. ${ }^{10}$ Poelmans et al. ${ }^{18}$ explained that this association was due to a structural cause, as a horizontal, shorter Eustachian tube in children may increase the reflux of nasopharyngeal contents into the middle ear.

In the present study, ages ranged between 5 and 12 years old with a mean age of $8.4 \pm 1.2$ years old. The children involved in the present study were 22 females (44\%) and 28 males (56\%).

The prevalence of GERD in the present study was $58 \%$, as shown in - Fig. 1. This result was in accordance with a previous study conducted by Yüksel et al., ${ }^{7}$ who reported that $54.9 \%$ of children with OME had GERD. Also, Velepic et al. ${ }^{19}$ concluded that $\sim 60 \%$ of the children with tubotympanic disease complained of GERD. The same result was reported by several studies that determined that the prevalence of GERD in children with OME ranged from 55.6 to $64 \%{ }^{20,21}$ On the other hand, Abd El-Fattah et al. ${ }^{22}$ found that the percentage of GERD in OME was $17.6 \%$. The different result could be explained by different methodology in the study conducted by Abd El-Fattah et al. ${ }^{22}$ In that study, the children complaining of OME were submitted to ventilation tube, tonsillectomy and adenoidectomy, and then assessed $\mathrm{pH}$ after recovery from surgery. So, the effects of these procedures on GERD were not well established, as the best time for assessing $\mathrm{pH}$ must be before the surgery.

Three mechanisms could explain the increased prevalence of GERD in OME. The first and the most significant one is the harmful effect of acid contents on the mucosa, which results in mucosal swelling, hypersecretion, and ciliary dysfunction. The second mechanism is vagus nerve stimulation. The last one assumed a relation between Helicobacter pylori infection and OME. Several studies reported the presence of this bacterium in aspirates of the middle ear. ${ }^{23,24}$ The stimulation of $M u c 5 b$ gene expression in the middle ear epithelium by the acidic and proteolytic effect of refluxed pepsin in the middle ear, is considered another possible explanation for the association between the two disorders. ${ }^{25}$

One of the positive confirmations for the role of GERD in the pathogenesis of OME is the improvement of OME with antireflux treatment. According to the previous studies, the percentage of the improvement of the treatment was $~$ between 80 and $85 \%$ of the studied patients, which resulted in a reduction in the planned surgical procedures. ${ }^{21,26,27}$

In the present study, there is a statistically significant difference in audiometric and tympanometric findings before and after the intake of PPI. The percentage of the improvement of OME in the children with GERD positive are $52 \%$, and the improvement of the hearing thresholds was $68 \%$, as shown in - Table 3.

The improvement of the middle ear condition and the hearing level of the children occurred gradually. After 1 month of treatment, the OME was improved in 5 patients and the hearing thresholds reached normal levels in 4 patients. The level of improvement increased after 2 months of treatment; 9 patients recovered from OME and 10 patients had normal hearing thresholds. At the end of the study, improvement of OME was found in 15 patients (52\%) and improvement of hearing threshold was found in 17 patients (68\%). The present study was similar to a previous study conducted by McCoul et $\mathrm{al}^{17}$. They reported statistically significant improvements in hearing loss, tympanometry, and middle ear status after the intake of PPI; progress occurred in 28 of 37 children (76\%) at the second visit and in 6 of 10 children (60\%) at the third visit.

Table 3 Middle ear condition and hearing loss in the patients before and after antireflux treatment

\begin{tabular}{|l|l|l|l|l|}
\hline Number & & Before treatment & After treatment & -value \\
\hline Hearing loss & Present & 25 & $8(32 \%)$ & $0.00002212^{*}$ \\
& Absent & 4 & $21(68 \%)$ & \\
\hline Tympanometry & Type B/C in one or both ear & 29 & $14(48 \%)$ & $0.00002691^{*}$ \\
& Type A & 0 & $15(52 \%)$ & \\
\hline
\end{tabular}

$p \geq 0.05$ : nonsignificant..

${ }^{*} p<0.05$ : significant. 
Also, Dewan et al. ${ }^{4}$ demonstrated that lansoprazole administration has a significant enhancement in the pure tone threshold (PTA) and the speech recognition threshold with $33 \%$ improvement rate of the middle ear effusion by the end of 3 months of follow-up. In addition, Rosenfeld et al. ${ }^{28}$ stated a $28 \%$ improvement rate of effusion by the end of 3 months.

\section{Conclusions}

The present study specifies that GERD could have a significant etiologic role in the pathogenesis of OME, as a result of existing statistically significant enhancements in hearing thresholds, and tympanometric results.

One of the important constituents of the effective management of OME in children is the control of GERD. In persistent OME, the administration of PPI can set aside superfluous surgical treatment (as tympanostomy).

\section{Conflict of Interests}

The authors have no conflict of interests to declare.

\section{References}

1 Miura MS, Mascaro M, Rosenfeld RM. Association between otitis media and gastroesophageal reflux: a systematic review. Otolaryngol Head Neck Surg 2012;146(03):345-352

2 Biagio L, Swanepoel DW, Laurent C, Lundberg T. Paediatric otitis media at a primary healthcare clinic in South Africa. S Afr Med J 2014;104(06):431-435

3 Birch L, Elbrønd O. Prospective epidemiological study of secretory otitis media in children not attending kindergarten. An incidence study. Int J Pediatr Otorhinolaryngol 1986;11(02):183-190

4 Dewan K, Lieu J. A Clinical Trial of Proton Pump Inhibitors to Treat Children with Chronic Otitis Media with Effusion. J Int Adv Otol 2018;14(02):245-249

5 Boers SA, de Zeeuw M, Jansen R, et al. Characterization of the nasopharyngeal and middle ear microbiota in gastroesophageal reflux-prone versus gastroesophageal reflux non-prone children. Eur J Clin Microbiol Infect Dis 2018;37(05):851-857

6 Poelmans J, Tack J, Feenstra L. Prospective study on the incidence of chronic ear complaints related to gastroesophageal reflux and on the outcome of antireflux therapy. Ann Otol Rhinol Laryngol 2002;111(10):933-938

7 Yüksel F, Doğan M, Karataş D, Yüce S, Şentürk M, Külahli I. Gastroesophageal reflux disease in children with chronic otitis media with effusion. J Craniofac Surg 2013;24(02):380-383

8 Heavner SB, Hardy SM, White DR, Prazma J, Pillsbury HC III. Transient inflammation and dysfunction of the eustachian tube secondary to multiple exposures of simulated gastroesophageal refluxant. Ann Otol Rhinol Laryngol 2001;110(10):928-934

9 White DR, Heavner SB, Hardy SM, Prazma J. Gastroesophageal reflux and eustachian tube dysfunction in an animal model. Laryngoscope 2002;112(06):955-961

10 Tasker A, Dettmar PW, Panetti M, Koufman JAP, P Birchall J, Pearson JP. Is gastric reflux a cause of otitis media with effusion in children? Laryngoscope 2002;112(11):1930-1934

11 Vandenplas Y, Rudolph CD, Di Lorenzo CNorth American Society for Pediatric Gastroenterology Hepatology and Nutrition European Society for Pediatric Gastroenterology Hepatology and Nutrition. et al; Pediatric gastroesophageal reflux clinical practice guidelines: joint recommendations of the North American Society for Pediatric Gastroenterology, Hepatology, and Nutrition (NASPGHAN) and the European Society for Pediatric Gastroenterology, Hepatology, and Nutrition (ESPGHAN). J Pediatr Gastroenterol Nutr 2009;49(04): 498-547

12 Contencin P, Narcy P. Nasopharyngeal pH monitoring in infants and children with chronic rhinopharyngitis. Int J Pediatr Otorhinolaryngol 1991;22(03):249-256

13 Inadomi JM, Fendrick AM. PPI use in the OTC era: who to treat, with what, and for how long? Clin Gastroenterol Hepatol 2005;3 (03):208-215

14 Lieu JE, Muthappan PG, Uppaluri R. Association of reflux with otitis media in children. Otolaryngol Head Neck Surg 2005;133 (03):357-361

15 Hellström S, Groth A, Jörgensen F, et al. Ventilation tube treatment: a systematic review of the literature. Otolaryngol Head Neck Surg 2011;145(03):383-395

16 Beyea JA, Paradis J, Nguyen P, Hall SF. Association of Tympanostomy Tubes With Future Risk of Advanced Ear Surgery-A Population Study. Otol Neurotol 2019;40(04):478-484

17 McCoul ED, Goldstein NA, Koliskor B, Weedon J, Jackson A, Goldsmith AJ. A prospective study of the effect of gastroesophageal reflux disease treatment on children with otitis media. Arch Otolaryngol Head Neck Surg 2011;137(01):35-41

18 Poelmans J, Tack J, Feenstra L. Chronic middle ear disease and gastroesophageal reflux disease: a causal relation? Otol Neurotol 2001;22(04):447-450

19 Velepic M, Rozmanic V, Velepic M, Bonifacic M. Gastroesophageal reflux, allergy and chronic tubotympanal disorders in children. Int J Pediatr Otorhinolaryngol 2000;55(03):187-190

20 Rozmanic V, Velepic M, Ahel V, Bonifacic D, Velepic M. Prolonged esophageal $\mathrm{pH}$ monitoring in the evaluation of gastroesophageal reflux in children with chronic tubotympanal disorders. J Pediatr Gastroenterol Nutr 2002;34(03):278-280

21 van den Abbeele T, Couloigner V, Faure C, Narcy P. The role of $24 \mathrm{~h}$ $\mathrm{pH}$-recording in pediatric otolaryngologic gastro-esophageal reflux disease. Int J Pediatr Otorhinolaryngol 2003;67(Suppl 1): S95-S100

22 Abd El-Fattah AM, Abdul Maksoud GA, Ramadan AS, Abdalla AF, Abdel Aziz MM. Pepsin assay: a marker for reflux in pediatric glue ear. Otolaryngol Head Neck Surg 2007;136(03):464-470

23 American Academy of Family Physicians. American Academy of Otolaryngology- Head and Neck Surgery; American Academy of Pediatrics Subcommittee on Otitis Media With Effusion. Otitis media with effusion. Pediatrics 2004;113:1412-1429

24 Yilmaz MD, Aktepe O, Cetinkol Y, Altuntaş A. Does Helicobacter pylori have role in development of otitis media with effusion? Int J Pediatr Otorhinolaryngol 2005;69(06):745-749

25 Doğru M, Kuran G, Haytoğlu S, Dengiz R, Arıkan OK. Role of laryngopharyngeal reflux in the pathogenesis of otitis media with effusion. J Int Adv Otol 2015;11(01):66-71

26 Phipps CD, Wood WE, Gibson WS, Cochran WJ. Gastroesophageal reflux contributing to chronic sinus disease in children: a prospective analysis. Arch Otolaryngol Head Neck Surg 2000;126 (07):831-836

27 Bothwell MR, Parsons DS, Talbot A, Barbero GJ, Wilder B. Outcome of reflux therapy on pediatric chronic sinusitis. Otolaryngol Head Neck Surg 1999;121(03):255-262

28 Rosenfeld RM, Kay D. Natural history of untreated otitis media. Laryngoscope 2003;113(10):1645-1657 